Revue Revue de l'histoire des religions

del'histoire des religions

$1 \mid 2019$

Corps, ascèse et extinction dans l'histoire du bouddhisme (Inde, Corée, Japon)

Yann RAISON DU CLEUZIOU, De la contemplation à la contestation. La politisation des dominicains de la Province de France (années 1940-1970)

Paris, Éditions Belin (« Socio-histoires »), 2016

Tangi Cavalin

(2) OpenEdition

Journals

Édition électronique

URL : https://journals.openedition.org/rhr/9749

DOI : $10.4000 /$ rhr.9749

ISSN : 2105-2573

Éditeur

Armand Colin

Édition imprimée

Date de publication : 1 mars 2019

Pagination : 227-230

ISBN : 978-2-200-93230-5

ISSN : 0035-1423

Référence électronique

Tangi Cavalin, « Yann RaIson du CLeuzıou, De la contemplation à la contestation. La politisation des dominicains de la Province de France (années 1940-1970) », Revue de l'histoire des religions [En ligne], 1 I 2019, mis en ligne le 01 janvier 2021, consulté le 08 janvier 2022. URL : http://

journals.openedition.org/rhr/9749; DOl : https://doi.org/10.4000/rhr.9749

Ce document a été généré automatiquement le 8 janvier 2022.

Tous droits réservés 


\title{
Yann RAISON DU CLEUZIOU, De la contemplation à la contestation. La politisation des dominicains de la Province de France (années 1940-1970)
}

\author{
Paris, Éditions Belin (« Socio-histoires »), 2016
}

Tangi Cavalin

\section{RÉFÉRENCE}

Yann RAISON DU CLEUZIOU, De la contemplation à la contestation. La politisation des dominicains de la Province de France (années 1940-1970), Paris, Éditions Belin (« Socio-histoires »), 2016, $22 \mathrm{~cm}, 381$ p., $29 €$, ISBN 978-2-7011-6509-7.

Maître de conférences en science politique, Yann Raison du Cleuziou fait le choix dans l'ouvrage issu de sa thèse d'une analyse des années 1968 circonscrite aux dominicains, étudiés dans le cadre de la province dite de France, la plus importante numériquement des trois provinces hexagonales. La définition d'un champ d'étude en apparence étroit repose sur la conviction qu'il est un observatoire judicieux des ressorts cléricaux de la « crise catholique » (Denis Pelletier). C'est dire que l'enquête, loin de se cantonner aux engagements ouvertement politiques de quelques figures, explore les transformations de l'identité dominicaine qui les ont rendus possibles. Le fil rouge de la démonstration est que la province n'a pas subi la crise des années 1968, mais qu'elle a été mise en crise, d'une manière plus ou moins contrôlée, par ses propres responsables, ce qui justifie une analyse sociologique voire socio-historique du fonctionnement interne de l'institution. La réflexion historique sur les événements n'est pas ignorée (quel sens, pour ne citer qu'un exemple, conférer au "drapeau rouge » hissé par un étudiant le 14 mai 1968 au sommet du clocher du Saulchoir ?), mais la démarche de l'auteur privilégie plutôt le 
décentrement à l'égard de ce qu'a privilégié la mémoire de l'ordre. Trois points sont particulièrement significatifs de ce point de vue.

2 En premier lieu, la génération des dominicains contestataires n'a pu peser sur le devenir de la province que parce qu'elle a été encouragée en ce sens par ses aînés : ceux-ci, entrés dans l'ordre dans les années 1940 subissent les effets de la purge de février 1954 qui instaure un lourd climat de suspicion jusqu'à l'arrivée aux commandes provinciales de Joseph Kopf en 1957. Empêchés de réaliser leur vocation sur le terrain missionnaire ou la recherche théologique, ces religieux, une fois parvenus aux responsabilités, reportent sur la génération suivante leurs aspirations apostoliques et développent une «juvénophilie» justifiée par les mutations à l'œuvre dans la société. C'est cependant moins au nom d'une vague affinité avec l'esprit du temps que les étudiants dominicains se voient parés de tous les espoirs par leurs formateurs, que parce qu'ils offrent à la génération précédente l'opportunité de renverser en leur faveur le rapport de force : loin d'être brimées au nom des traditions, leurs velléités contestataires sont, dès le noviciat, encouragées à rebours du modèle traditionnel de formation reposant sur l'incorporation de normes qualifiées de monastiques.

3 La seconde opération de décentrement consiste à prêter attention, plus qu'aux théologiens qui ont fait la gloire de l'ordre, à ses administrateurs car ce sont eux qui tiennent les commandes de la province au cours des années 1968 et portent la responsabilité de la crise. Deux figures émergent parmi ces officiers: Albert-Marie Besnard, successivement maître des novices et des étudiants (1959-1968) qui, «de défenseur de l'institution auprès des jeunes, [...] devient un défenseur des jeunes dans l'institution" et, surtout, Nicolas Rettenbach, maître des étudiants (1940-1955) et provincial (1967-1975), "porte-parole des jeunes». Lorsque des théologiens dominicains sont étudiés, comme Claude Geffré, Jacques Pohier ou encore Philippe Roqueplo, l'analyse tourne résolument le dos à la traditionnelle histoire des idées et les disputes spirituelles et théologiques sont toujours référées aux enjeux institutionnels qui leur donnent sens.

4 En définitive, c'est la politisation des dominicains au cours des années 1968 qui est reliée à ce qui la fonde religieusement : une subversion de la vocation religieuse et de ses instruments de perpétuation (mise en sommeil du noviciat, fermeture du couvent d'études). De ce point de vue, peu importe que ceux qui s'engagent politiquement ne soient qu'une poignée, pas plus que ne comptent pour eux-mêmes les multiples départs de dominicains après 1968 justifiés ou non par les remises en cause du célibat. Car ce qui se joue alors, c'est le ralliement, au nom de l'Évangile qui justifie toutes les contestations, de la jeune génération à une logique religieuse «intra-mondaine » contre celle, "extra-mondaine ", défendue par leurs aînés. La reconstitution, qui s'appuie notamment sur Albert O. Hirschman (exit, loyalty, voice), des positions des dominicains, enregistre les effets destructeurs pour l'institution de ce changement de régime de vérité : menace de sécession de couvents traditionnels (l'Annonciation à Paris), transfiliations à d'autres provinces (Toulouse, Lombardie), défections de personnalités comme Louis-Bertrand Guérard des Lauriers ou Marie-Dominique Philippe qui, chacun à leur manière, réinventent ailleurs l'ordre dominicain de leur jeunesse... La crise ne s'épuise, au bout d'une décennie, qu'au prix du départ des plus radicaux des deux bords, loin d'une institution qui ne peut plus prétendre incarner l'idéal religieux dans lequel ils se reconnaissent. Pour ceux qui restent, il n'y a pas non plus de retour en arrière : le pluralisme des interprétations de la vie dominicaine, voté 
au chapitre provincial de 1969 afin de permettre aux jeunes prêcheurs d'expérimenter de nouvelles formes de vie, est devenu le mode de régulation nécessaire au maintien d'une fragile unité. Comme le souligne l'auteur, elle a peu à voir avec un quelconque ralliement à l'individualisme contemporain. Elle sanctionne l'échec des dominicains à se rassembler autour d'une identité commune. Quant aux observances traditionnelles, nul n'envisage de les restaurer sinon au cas par cas.

5 Se refusant à être une histoire de la province de France, l'étude entend donner ses lettres de noblesse à une "histoire politique de la spiritualité catholique». On serait passé, selon le titre, "de la contemplation à la contestation». Ce raccourci suscite la gêne parce qu'en suggérant l'évolution sans retour d'une pratique spirituelle à une activité politique, il postule une vision réductrice de l'histoire de l'ordre avant la crise. D'une part, parce qu'une contestation récurrente l'anime quant à la détermination de la "vraie» vie conventuelle. Sans remonter aux réformes de Sébastien Michaëlis à l'époque moderne, les décennies qui précèdent l'étude fournissent plusieurs exemples de cette tension, à commencer par le conflit des années 1850 entre Lacordaire et Jandel autour de questions touchant au type d'ascèse nécessaire aux religieux dans une société - déjà ! - en pleine mutation ou, plus proche, cet autre épisode politique aux ressorts religieux complexes qu'est la crise d'Action française. D'autre part, au sein de l'Église catholique, la vie dominicaine se caractérise par des spécificités (durée des études, dispenses, mode de gouvernement démocratique, exigences apostoliques, assignation dans des couvents successifs, contacts avec les milieux universitaires) qui permettent l'affirmation de fortes personnalités parfaitement aptes, bien avant les années 1940, à créer des réseaux affinitaires et protestataires excellant dans l'exégèse des normes constitutionnelles. Et si l'on regrette l'absence dans ce travail d'une prosopographie, c'est parce que l'analyse générationnelle et l'attention au conflit autour des normes polarisent à tel point la démonstration que les itinéraires de certains religieux (on pense à Henri Féret, André Duval, Pierre de Contenson) perdent en lisibilité en ne trouvant place que du côté du conservatisme dès lors qu'ils manifestent un attachement pourtant complexe à une forme de vie conventuelle.

6 Il convient également d'intégrer à l'analyse le fait que les archives dominicaines (dont la question du conflit n'épuise pas la richesse), ici libéralement ouvertes, recèlent de tels trésors de querelles internes. Ceux (comme Jourdain de Rudder, l'un des opposants les plus résolus aux contestataires) qui ont contribué à les rassembler et à les classer, l'ont fait avec la conviction que les historiens s'en serviraient pour rendre compte des erreurs de leurs adversaires. Battus sur le terrain du pouvoir et de la prise de parole, ils ont fait le pari que l'histoire justifierait leur forme de vie. Les archives ne se contentent donc pas d'enregistrer les luttes, elles en sont le prolongement et peuvent en devenir l'objet. La vigilance historienne ne cesse décidément d'être de mise à qui veut intervenir dans l'écriture de la « crise catholique ».

7 Finissons sur un vrai regret formel. L'ouvrage offre au lecteur plusieurs annexes dont le principe est fort bienvenu. Il est d'autant plus dommage que, à l'instar de l'ensemble du travail éditorial, elles n'aient été plus soignées. Tandis que l'index des noms propres en omet beaucoup (Jacques Lagroye, à la mémoire duquel le livre est pourtant dédié, en est absent), la carte des couvents donne à voir des implantations disparues au moment de la crise dont l'ouvrage rend compte, et le graphique des effectifs de la page 326 est incompréhensible (spectaculaire remontée des effectifs en 1997) faute de commentaire rappelant la fusion des provinces de France et de Lyon à cette date. 